\title{
Clinical and virological factors associated with gastrointestinal symptoms in patients with acute respiratory infection: a two-year prospective study in general practice medicine
}

Laetitia Minodier ${ }^{1}$, Shirley Masse ${ }^{1}$, Lisandru Capai ${ }^{1}$, Thierry Blanchon ${ }^{2,3}$, Pierre-Emmanuel Ceccaldi ${ }^{4,5,6}$, Sylvie van der Werf ${ }^{5,7,8}$, Thomas Hanslik ${ }^{9,10,11}$, Remi Charrel ${ }^{12}$ and Alessandra Falchi ${ }^{{ }^{*}}$

\begin{abstract}
Background: Gastrointestinal (Gl) symptoms, such as diarrhea, vomiting, abdominal pain and nausea are not an uncommon manifestation of an acute respiratory infection (ARI).

We therefore evaluated clinical and microbiological factors associated with the presence of Gl symptoms in patients consulting a general practitioner (GP) for ARI.

Methods: Nasopharyngeal swabs, stool specimens and clinical data from patients presenting to GPs with an ARI were prospectively collected during two winter seasons (2014-2016). Samples were tested by quantitative real-time PCR for 12 respiratory pathogen groups and for 12 enteric pathogens.

Results: Two hundred and four of 331 included patients (61.6\%) were positive for at least one respiratory pathogen. Sixty-nine stools (20.8\%) were positive for at least one pathogen (respiratory and/or enteric). Gl symptoms were more likely declared in case of laboratory confirmed-enteric infection (adjusted odds ratio (aOR) $=3.2 ; 95 \%$ confidence interval [CI] [1.2-9.9]; $p=0.02$ ) or human coronavirus (HCoV) infection ( $\mathrm{aOR}=2.7 ;$; $1.2-6.8] ; p=0.02)$. Consumption of antipyretic medication before the consultation seemed to reduce the risk of developing $\mathrm{Gl}$ symptoms for patients with laboratoryconfirmed influenza (aOR=0.3; [0.1-0.6]; $p=0.002)$.
\end{abstract}

Conclusions: The presence of Gl symptoms in ARI patients could not be explained by the detection of respiratory pathogens in stools. However, the detection of enteric pathogens in stool samples could explained by the presence of Gl symptoms in some of ARI cases. The biological mechanisms explaining the association between the presence of HCoVs in nasopharynx and Gl symptoms need to be explored.

Keywords: Acute respiratory infection, Gastrointestinal symptoms, Enteric pathogens, Influenza virus, General practitioner

\footnotetext{
*Correspondence: falchi@univ-corse.fr

${ }^{1}$ EA7310, Laboratoire de Virologie, Université de Corse-Inserm, 20250 Corte,

France

Full list of author information is available at the end of the article
} 


\section{Background}

Gastrointestinal (GI) symptoms, such as diarrhea, vomiting, abdominal pain and nausea are not an uncommon manifestation of an acute respiratory infection (ARI) [1-8] (Additional file 1) and have been reported as a hallmark of severe influenza in childhood [9].

Influenza viruses and other respiratory agents such as human rhinoviruses (HRV) [10], have been detected in stools of patients with ARIs (Additional file 2) [5, 10-14], but their correlation with GI symptoms and their viability in stool is still debated $[10,15]$.

There are several possible explanations for the observed GI symptoms during an ARI. First, each winter, ARIs and gastroenteritis outbreaks overlap, creating a spurious association between ARI and GI symptoms, maybe caused by a co-infection between respiratory agents and enteroviruses [16]. Second, GI symptoms may be a side effect of drug treatment (antibiotic or antiviral) [17, 18] or food consumption (ex: raw shellfish and molluscs) [19]. Third, GI symptoms could either be a manifestation of a direct viral effect, or an indirect viral effect of respiratory viruses, such as lung-derived CD4+ cell-induced dysbiosis resulting in intestinal injury [20].

Insufficient information about the prevalence of GI symptoms in ARIs, their clinical features and their potential risk factors may lead to diagnostic errors and inadequate treatment.

In the context of the above limitations, the main objectives of this two-year (2014-2016) prospective study were to evaluate the demographical, clinical and microbiological factors associated with the presence of GI symptoms in patients presenting to general practitioner (GP) with an ARI.

\section{Methods}

\section{Study design}

A representative sample of 60 GPs from the French Sentinelles Network [21, 22] was recruited to enrol ARI patients from all over mainland France.

To ensure that the selection of ARI patients remained random, each GP was required to include, each week, the first two patients seen in consultation who met the inclusion criteria, regardless of their age. The case definition of ARI was "any person with a sudden onset of symptoms and at least one of the following four systemic symptoms: fever ( $\geq 38{ }^{\circ} \mathrm{C}$ or greater) or history of fever ( $\geq 38{ }^{\circ} \mathrm{C}$ or greater) taken at home or feverishness, malaise, headache, myalgia, AND at least one of the following three respiratory symptoms: cough, sore throat, or shortness of breath" [23]. All patients were recruited within $48 \mathrm{~h}$ of the onset of symptoms.

Patients were enrolled by their GPs over two consecutive ARI seasons from week 46, 2014 (10-16 November 2014) to week 15, 2015 (06-12 April 2015) and from week 45, 2015 (02-8 November 2015) to 16, 2016 (1824 April 2016) (Additional file 3).

The GPs completed a case report form (CRF) for all volunteers who met the case definition and agreed to participate, and submitted this by post (all items are listed on Additional file 4). We defined a patient as vaccinated if he/she had received at least one dose of seasonal influenza vaccine at least 15 days before the onset of ARI symptoms.

\section{Sample collection}

Two types of samples were obtained for each enrolled patient: a nasopharyngeal swab and a stool sample. The nasopharyngeal specimen was collected by the GP and was sent with the CRF to the test laboratory by post in a triplepackaged Copan universal transport medium (UTM-RT) container (Copan Italia, Brescia, Italy). Included patients were asked to collect stool specimens and send them to the laboratory within $48 \mathrm{~h}$ by post in triple packaging as required by the United Nations class 6.2 specifications.

\section{Laboratory investigations Nucleic acid extraction}

For nasopharyngeal specimens, nucleic acids were extracted from $200 \mu \mathrm{l}$ of UTM-stored sample and eluted in $60 \mu$ l of elution buffer using QiAamp MinElute virus spin kits (Qiagen, France) according to the manufacturer's instructions. Stool specimens were centrifuged at $14,000 \mathrm{xg}$ for $20 \mathrm{~min}$; then nucleic acids were extracted from $200 \mu \mathrm{l}$ of the UTM-stored sample and eluted in $40 \mu$ of elution buffer using QiAamp MinElute virus spin kits (Qiagen) according to the manufacturer's instructions. An internal control (T4 and MS2 phages) was added to each extraction tube to assess the quality of the extraction at the end of the amplification [24].

\section{Detection of respiratory pathogens}

All extracted samples (nasopharyngeal and stool) were screened for influenza A and B viruses by real-time quantitative Reverse Transcription PCR (RT-qPCR); influenza $A$ virus-positive specimens were subtyped and influenza $B$ virus-positive samples were analysed for Victoria and Yamagata lineage according to the method developed by the French National Influenza Centre $[25,26]$. Then, the presence of 10 non-influenza respiratory pathogen groups was analysed by RT-qPCR and qPCR using a Fast Track Diagnostic (FTD) Respiratory pathogens 21 kit (Fast Track Diagnostic, Luxemburg) using five tubes containing primer and probe mix for different viruses; Tube-1 [Influenza $A$, Influenza $A$ subtype H1N1 (A(H1N1)pdm09), human Rhinovirus (HRV), Influenza B], Tube-2 [human Coronaviruses NL63 (HCoV-NL63), 229E (HCoV 229E), OC43 (HCoV-OC43), and HKU1 (HCoV HKU1)], Tube-3 [human Parainfluenza viruses, 2, 3, and 4 (HPIV- 2, 3 and 4) 
\& Internal Control], Tube-4 [human Parainfluenza viruses-1, Mycoplasma pneumoniae (M.pneu), human Bocavirus (HBoV), human Metapneumovirus (HMPV A/B)] and Tube5 [Respiratory Syncytial virus (RSVA/B), human Adenovirus (HAdV), Enterovirus (EV), human Parechovirus (HPeV)].

\section{Detection of enteric pathogens}

Extracted stool samples were screened by RT-qPCR and qPCR using the FTD Viral gastroenteritis kit (Fast Track Diagnostic, Luxemburg) according to the manufacturer's instructions, using three multiplex PCRs to detect six viruses: human norovirus (hNoVG1 and hNoVG2), adenovirus (hAdV), human astrovirus (HAstV), rotavirus (RV) and sapovirus $(\mathrm{SaV})$. The panel FTD Bacterial gastroenteritis kit (Fast Track Diagnostic, Luxemburg) was used following the manufacturer's procedure, using two multiplex RT-qPCR for six bacteria: Campylobacter coli/ jejuni/lari, Escherichia coli verotoxin positive, Salmonella spp., Shigella spp. + enteroinvasive Escherichia coli, Yersinia enterocolitica, Clostridium difficile. Two different positives controls for viral and bacterial multiplex RTqPCR reactions and a negative control tube are provided in these kits.

\section{Statistical analysis}

Quantitative variables were described by using means [Min-Max] and standard deviations were compared by the Wilcoxon test. Qualitative variables were described by using proportions and compared using a chi-square or Fisher's exact test if the chi-square test was not applicable; the results were presented as odds ratio with 95\% confidence intervals (OR [95\% CI]). We used unconditional logistic regression model to study the factors associated with SGI in ARI patients (yes/no) by comparing independent effects of factors that were associated in the bivariate analyses ( $p$-value of $<0.20$ ). Variables for the model were chosen through automatic backwards selection using a significance level of 0.05 . Bivariate and multivariate analyses were performed on patients with only one pathogen detected in nasopharyngeal swabs and/or in stool sample. All analyses were been performed using the R program (http://www.r-project.org).

\section{Results}

During the study period, 47 of the 60 recruited GPs (78.3\%) that agreed to participate in the study enrolled at least one ARI patient. Of the 574 ARI patients recruited by these GPs, 331 (57.6\%) sent a stool sample to the virology laboratory and finalized their inclusion in this study (Fig. 1). There were no significant differences in socio-demographic and clinical characteristics or positivity rate for the analysed pathogens between the 574 ARI patients initially recruited by the GPs and the 331

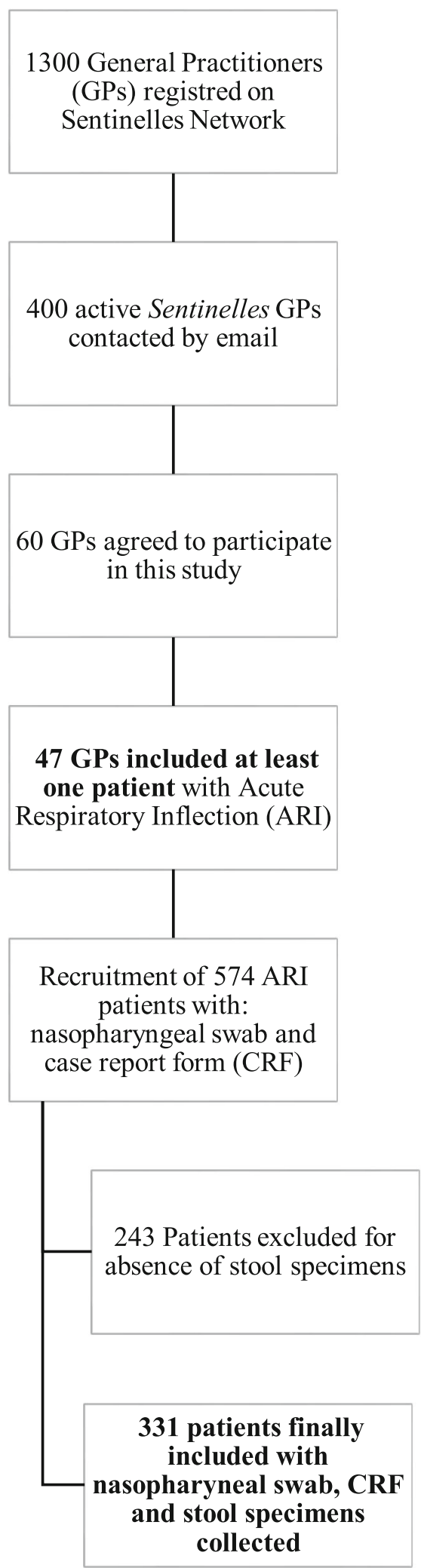

Fig. 1 Flow diagram describing selection of patients included in the study 
Table 1 Comparison of demographical, clinical and microbiological characteristics between patients initially recruited by General Practitioners (GPs) with at least a nasopharyngeal swab $(N=574)$ and patients included in the study as presenting a nasopharyngeal swab and a stool specimen $(N=331)$

\begin{tabular}{|c|c|c|c|}
\hline Characteristics & $\begin{array}{l}\text { Patients with } \\
\text { at least a } \\
\text { nasopharyngeal } \\
\text { sample } \\
\mathrm{N}(\%)\end{array}$ & $\begin{array}{l}\text { Patients with } \\
\text { nasopharyngeal } \\
\text { and stool sample } \\
\mathrm{N}(\%)\end{array}$ & $P$-value \\
\hline Number of samples & 574 & 331 & \\
\hline Male & $268(46.7)$ & $154(46.5)$ & $P>0$ \\
\hline Mean age [Min-Max] & $35.9[1-91]$ & $35.8[1-91]$ & $P>0$ \\
\hline $0-4$ y & $38(6.6)$ & $25(7.5)$ & $P>0$ \\
\hline $5-14 y$ & $66(11.5)$ & $59(17.8)$ & $P>0$ \\
\hline $15-44$ y & $241(42)$ & $122(36.8)$ & $P>0.0$ \\
\hline $45-64$ y & $141(24.6)$ & $86(26)$ & $P>0$ \\
\hline$\geq 65 y$ & $66(11.5)$ & 39 (11.8) & $P>0$. \\
\hline $\begin{array}{l}\text { Vaccination against } \\
\text { influenza }\end{array}$ & $51(8.9)$ & $36(10.9)$ & $P>0$ \\
\hline Travel (<15 days) & $29(5)$ & $20(6)$ & $P>0$ \\
\hline Risk factor & $223(38.8)$ & $124(37.5)$ & $P>0$ \\
\hline Chronic disease & $189(32.9)$ & $106(32)$ & $P>0$ \\
\hline Depression & $51(8.9)$ & $26(7.8)$ & $P>0$ \\
\hline Hospitalization & $35(6.1)$ & $20(6)$ & $P>0$. \\
\hline $\begin{array}{l}\text { Digestive disorders } \\
<7 \text { days }\end{array}$ & $103(17.9)$ & $59(17.8)$ & $P>0$. \\
\hline \multicolumn{4}{|l|}{ Symptoms } \\
\hline High Fever $\left(>39^{\circ} \mathrm{C}\right)$ & $275(47.9)$ & $156(47.1)$ & $P>0$. \\
\hline Asthenia & $507(88.3)$ & $288(87)$ & $P>0$. \\
\hline Myalgia & $431(75.1)$ & $243(73.1)$ & $P>0.0$ \\
\hline Headaches & $424(73.9)$ & $244(73.1)$ & $P>0$. \\
\hline Otitis & $62(10.8)$ & $28(8.5)$ & $P>0.0$ \\
\hline Dyspnea & $127(22.1)$ & $73(22)$ & $P>0$. \\
\hline Cough & $510(88.8)$ & $299(90.3)$ & $P>0$. \\
\hline Expectoration & $196(31.2)$ & $103(31.1)$ & $P>0.05$ \\
\hline Rhinitis & $426(74.2)$ & $251(75.8)$ & $P>0$ \\
\hline Pharyngitis & 338 (58.9) & $198(59.8)$ & $P>0.0$ \\
\hline Hyperemia & $150(26.1)$ & $81(24.5)$ & $P>0$ \\
\hline Adenopathy & $66(11.5)$ & 35 (10.6) & $P>0$. \\
\hline Dehydration & $6(1)$ & $4(1.2)$ & $P>0$ \\
\hline $\begin{array}{l}\text { Gastrointestinal } \\
\text { symptoms (SGI) }\end{array}$ & $327(57)$ & $189(57.1)$ & $P>0$ \\
\hline Diarrhea & 84 (14.6) & $47(14)$ & $P>0.05$ \\
\hline Vomiting & $66(11.5)$ & $28(8.5)$ & $P>0.0$ \\
\hline Nausea & 195 (34) & 105 (31.7) & $P>0.05$ \\
\hline Abdominal pain & $197(34.3)$ & $113(34.1)$ & $P>0.05$ \\
\hline \multicolumn{4}{|l|}{ Food consumption } \\
\hline & $37(6.4)$ & $25(7.5)$ & \\
\hline
\end{tabular}

Table 1 Comparison of demographical, clinical and microbiological characteristics between patients initially recruited by General Practitioners (GPs) with at least a nasopharyngeal swab $(N=574)$ and patients included in the study as presenting a nasopharyngeal swab and a stool specimen $(N=331)$ (Continued)

\begin{tabular}{lcll}
\hline Characteristics & $\begin{array}{c}\text { Patients with } \\
\text { at least a } \\
\text { nasopharyngeal } \\
\text { sample } \\
\text { N (\%) }\end{array}$ & $\begin{array}{l}\text { Patients with } \\
\text { nasopharyngeal } \\
\text { and stool sample } \\
N(\%)\end{array}$ & $P$-value \\
\hline $\begin{array}{l}\text { Raw shellfish and } \\
\text { molluscs }\end{array}$ & & \\
$\begin{array}{l}\text { Cooked shellfish and } \\
\text { molluscs }\end{array}$ & $51(8.9)$ & $31(9.4)$ & $P>0.05$ \\
$\begin{array}{l}\text { Tap water } \\
\text { Drug consumption before consultation }\end{array}$ & 198 (59.8) & $P>0.05$ \\
Antibiotics & $29(5)$ & $17(5.1)$ & $P>0.05$ \\
Antiviral & $16(2.8)$ & $8(2.4)$ & $P>0.05$ \\
Anti-inflammatory & $86(14.9)$ & $46(13.9)$ & $P>0.05$ \\
Antipyretics & $331(57.7)$ & $189(57.1)$ & $P>0.05$ \\
Other drugs & $104(18.1)$ & $64(19.3)$ & $P>0.05$ \\
Drug prescription after consultation & & \\
Antibiotics & $104(18.1)$ & $57(17.2)$ & $P>0.05$ \\
Antiviral & $48(8.4)$ & $24(7.2)$ & $P>0.05$ \\
Antipyretics & $473(82.4)$ & $271(81.9)$ & $P>0.05$ \\
Other drugs & $165(28.7)$ & $103(31.1)$ & $P>0.05$
\end{tabular}

Results of virological analyses in nasopharyngeal samples

Nasopharyngeal

samples positive to at

least one pathogen

Influenza $(A+B)$

$176(30.7)$

$114(34.4)$

$>0.05$

Influenza A (including

69 (12)

$42(12.7)$

$P>0.05$

4 A not subtyped)

A(H1N1)pdm09

$36(6.3)$

$24(7.2)$

$P>0.05$

A(H3N2)

$29(5)$

$14(4.2)$

$P>0.05$

Influenza B

107 (18.6)

$72(21.7)$

$P>0.05$

Influenza B Victoria

$89(15.5)$

57 (17.2)

$P>0.05$

Influenza B Yamagata

18 (3.1)

$15(4.5)$

$P>0.05$

Human Coronaviruses

$48(8.4)$

$35(10.6)$

$P>0.05$

NL63, 229E, OC43,

HKU1

Human Rhinovirus

$49(8.5)$

$25(7.5)$

$P>0.05$

Respiratory Syncytial

$26(4.5)$

$20(6)$

$P>0.05$

virus $A / B$

Human Bocavirus

$5(0.9)$

$3(0.9)$

$P>0.05$

Human

$16(2.8)$

$9(2.7)$

$P>0.05$

Metapneumovirus A/B

Human Parainfluenza

$6(1)$

$4(1.2)$

$P>0.05$

viruses 1, 2,3,4

Human Adenovirus

$8(1.4)$

$4(1.21)$

$P>0.05$ 
Table 1 Comparison of demographical, clinical and microbiological characteristics between patients initially recruited by General Practitioners (GPs) with at least a nasopharyngeal swab $(N=574)$ and patients included in the study as presenting a nasopharyngeal swab and a stool specimen ( $N=331$ ) (Continued)

\begin{tabular}{llll}
\hline Characteristics & $\begin{array}{l}\text { Patients with } \\
\text { at least a } \\
\text { nasopharyngeal } \\
\text { sample } \\
N(\%)\end{array}$ & $\begin{array}{l}\text { Patients with } \\
\text { nasopharyngeal } \\
\text { and stool sample } \\
N(\%)\end{array}$ & $P$-value* \\
\hline $\begin{array}{l}\text { Mycoplasma } \\
\text { pneumoniae }\end{array}$ & 0 & 0 & \\
$\begin{array}{l}\text { Enteroviruses } \\
\text { Co-infection }\end{array}$ & 0 & 0 & $P>0.05$ \\
\hline
\end{tabular}

${ }^{*} P$-value resulted of Chi square or Fisher exact test

ARI patients with nasopharyngeal and stool samples and completed CRF who were finally included (Table 1).

The demographic data and clinical characteristics of the 331 ARI cases studied are summarized in Table 1. At least one GI symptom was declared by 189 (57.1\%) of the 331 ARI patients: diarrhea was reported by 47 (14\%), vomiting by 28 (8.5\%), nausea by 105 (31.7\%) and abdominal pain by 113 (34.1\%) (Table 1$)$.

\section{Respiratory pathogens identified in nasopharyngeal samples}

Overall, the nasopharyngeal specimens of 204 of the 331 (61.6\%) patients were positive for at least one of the 12 respiratory pathogen groups analysed in this study (Table 1). Infection with a single virus accounted for $87.2 \%(194 / 204)$ of the positive nasopharyngeal samples, whereas infections with multiple viruses observed in 5\% (10/204) of them, including nine double infections: (A(H1N1)pdm09/HCoV, $\mathrm{ADV} / \mathrm{HBoV}$, two Influenza $\mathrm{B}$ virus $/ \mathrm{HCoV}$, two $\mathrm{HCoV} /$ HRVS and two HRV/HBoV) and one triple infection (HRV/ADV/HRSV) (Fig. 2a). The most frequently identified pathogen was influenza virus $(34.4 \%, 114 / 331$; consisting of influenza A virus [12.7\%, 42/331] and influenza B virus $[21.7 \%, 72 / 331])$, followed by $\mathrm{HCoV}(10.6 \%, 35 / 331)$, $\operatorname{HRV}(7.5 \%, 25 / 331)$ and RSV $(6.0 \%, 20 / 331)$ (Table 1 and Fig. 2a). Of the 35 samples that tested positives for $\mathrm{HCoV}$, 13 were $\mathrm{HCoV}-\mathrm{NL} 63,10 \mathrm{HCoV}-229 \mathrm{E}, 7 \mathrm{HCoV}-\mathrm{OC} 43$ and 5 HCoV-HKU1.

\section{Respiratory and enteric pathogens identified in stool samples}

Of the 331 stool samples, 69 (20.8\%) were positive for at least one pathogen (respiratory and/or enteric) (Fig. 2b). Of the 69 positive stool samples, 94.2\% (65/69) were positive for a single pathogen, whereas multiple viruses (all double infections) were detected in 5.8\% (4/69) of positive stool specimens (A(H3N2)/ADV, HBoV/ADV and two HRV/HBoV) (Fig. 2b).
The percentage of positive patients was highest for influenza viruses $(7.5 \%, 25 / 331)$, for enteric pathogens (7.5\%, 25/331) followed by $\operatorname{HRV}(3.9 \%, 13 / 331)$. HCoV (1 HCoV-NL63, 1 HCoV-229E, $1 \mathrm{HCoV-OC43} \mathrm{and} 1$ HCoV-HKU1), HBoV, HMPV and PIV were detected in fewer than $2 \%$ of the 331 stool specimens from ARI cases (Fig. 2b).

\section{Factors related to Gl symptoms}

All factors listed in Table 1 have been analysed to investigate association with GI symptoms in ARI patients. Table 2 shows factors significantly related to GI symptoms in ARI patients. Results of RNA/DNA positivity in stools between ARI patients with and without GI symptoms for the respiratory pathogens tested were also reported in Table 2 .

ARI patients who reported at least one GI symptom (57.1\%; 189/331) were associated with the presence of high fever $\left(>39^{\circ} \mathrm{C}\right)$ (adjusted odds ratio [aOR] $=1.795 \%$ confidence interval [CI] [1.1-2.7]; $p=0.03)$, and headaches $(\mathrm{aOR}=2.0[1.2-3.4] ; p=0.003)$ (Table 2).

ARI patients with GI symptoms were more likely to have at least one enteric infection $(\mathrm{aOR}=3.2$ [1.2-9.9]; $p=0.02$ ) detected in stool or to have an infection with $\mathrm{HCoV}$ detected in the nasopharynx $(\mathrm{aOR}=2.7$; $[1.2-$ 6.8]; $p=0.002$ ) (Table 2). Proportion of GI symptoms in ARI patients with single infection ranged from $33.3 \%$ with HRV infection (in nasopharyngeal swab) to $79.2 \%$ with enteric pathogens infection (in stool specimens) (Table 3). ARI patients with $\mathrm{HCoV}$ detected in the nasopharynx or enteric pathogen detected in stool were statistically more likely to have GI symptoms than ARI patients with other respiratory pathogens infection (Table 3). Among the 104 ARI patients with laboratoryconfirmed influenza at least in the nasopharynx, 56.7\% (59/104) had GI symptoms (Table 2). Consumption of antipyretic medication before the consultation seemed to reduce the risk of developing GI symptoms for this population ( $\mathrm{aOR}=0.3[0.1-0.6] ; p=0.002$ ) (Table 2 ).

\section{Discussion}

In this study, results showed that the presence of GI symptoms in ARI patients could not be explained by the detection of respiratory pathogens in stools. However, GI symptoms were more common among patients with ARI who were exclusively infected with $\mathrm{HCoV}$ detected in nasopharyngeal sample. This association cannot be explained by the presence of $\mathrm{HCoVs}$ in stools because the simultaneous detection of $\mathrm{HCoV}$ in nasopharyngeal and stool specimens was sporadic.

Even if the association of GI symptoms with enteric infections is not surprising, it is interesting to point out that $13.2 \%(25 / 189)$ of ARI infections with GI symptoms 


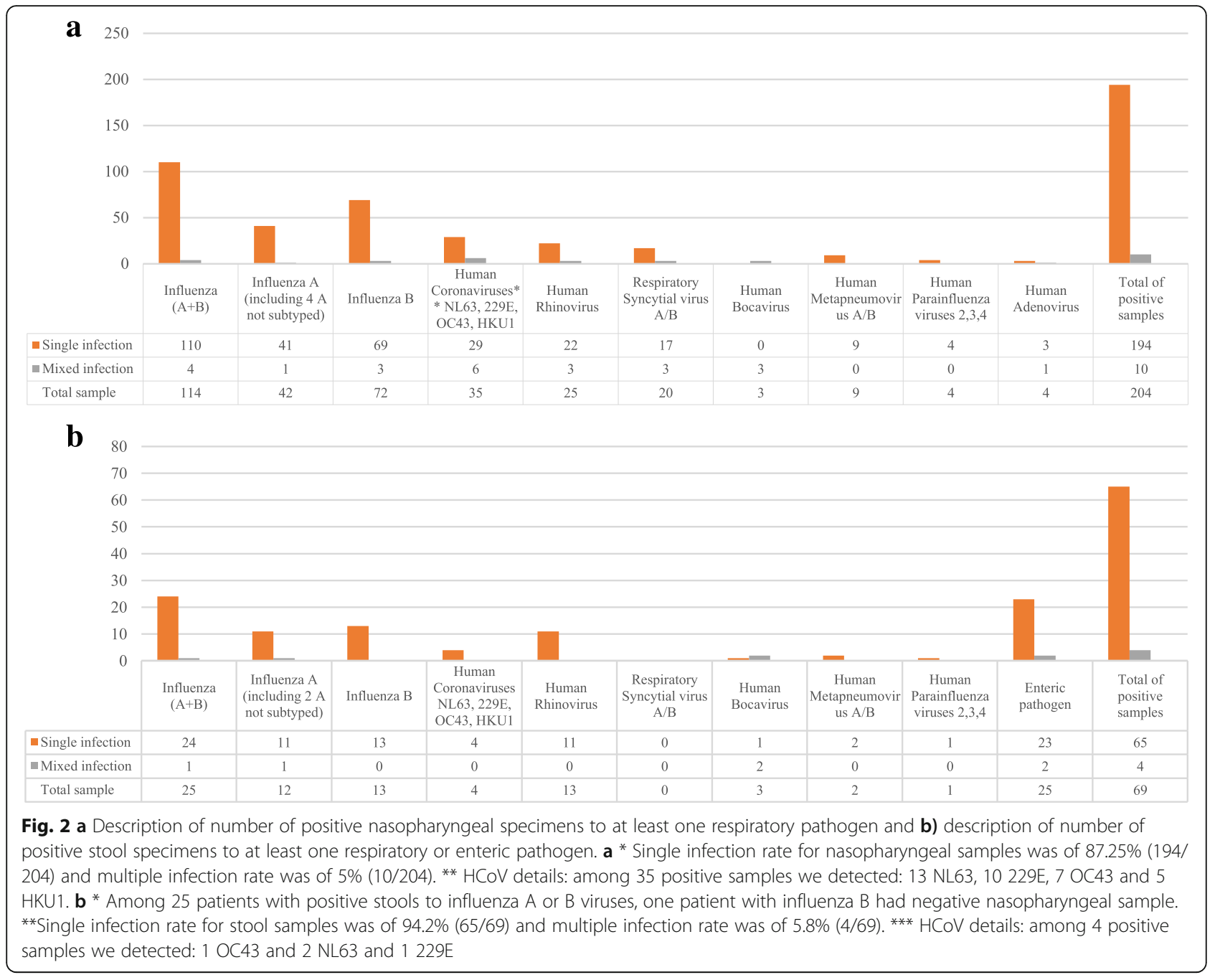

were associated with laboratory-confirmed enteric infections. This result suggests that GI symptoms in patients with ARI could be related to enteric infections, and that the positive correlation between GI symptoms and fever or headache observed in this study increases the difficulty of clinical diagnosis.

We detected, HCoVs in $10.6 \%$ of nasopharyngeal samples of patients with ARI. These results are in line with previous studies reporting $\mathrm{HCoVs}$ in $2.1 \%-18 \%$ of respiratory samples [27] of ARI patients. In the present study, patients with $\mathrm{HCoVs}$ featured $11.6 \%$ of ARI patients with GI symptoms. Moreover $78.9 \%$ of patients with $\mathrm{HCoV}$ infection declared to have GI symptoms. Although $\mathrm{HCoVs}$ are recognized as causes of respiratory infection, their role in gastrointestinal infection remains uncertain and a subject of debate [12, 28, 29]. In the present study, GI symptoms were positively associated with single laboratory-confirmed $\mathrm{HCoV}$ infection detected in the nasopharynx of ARI patients. This association cannot be explained by the presence of $\mathrm{HCoVs}$ in stools because the simultaneous detection of $\mathrm{HCoV}$ in nasopharyngeal and stool specimens was observed in four patients only. The four commonly circulating HCoVs (1 HCoV-NL63, 1 HCoV-229E, 1 HCoV-OC43 and $1 \mathrm{HCoV}-\mathrm{HKU} 1)$ were detected in stool samples, thus none of the four $\mathrm{HCoV}$ could be specifically associated with positivity of stools. The proportion of $\mathrm{HCoVs}$ in stool specimens was less important than it was in nasopharyngeal specimens (4 versus 28 respectively) which hampered an efficient comparison of the results and limited their interpretation. Moreover there was no ARI patient presenting $\mathrm{HCoV}$ in stools in the absence of $\mathrm{HCoV}$ in nasopharynx. Therefore the presence of $\mathrm{HCoV}$ RNA in stool is likely due to swallowing rather than due to local replication in the GI tract [12]. The presence of HCoVs in nasopharynx seems to be linked to GI symptoms in ARI patients but the biological mechanism remained unclear. In line with previous studies [13], no association was observed between seasonal influenza virus detection in nasopharyngeal or stool samples and 


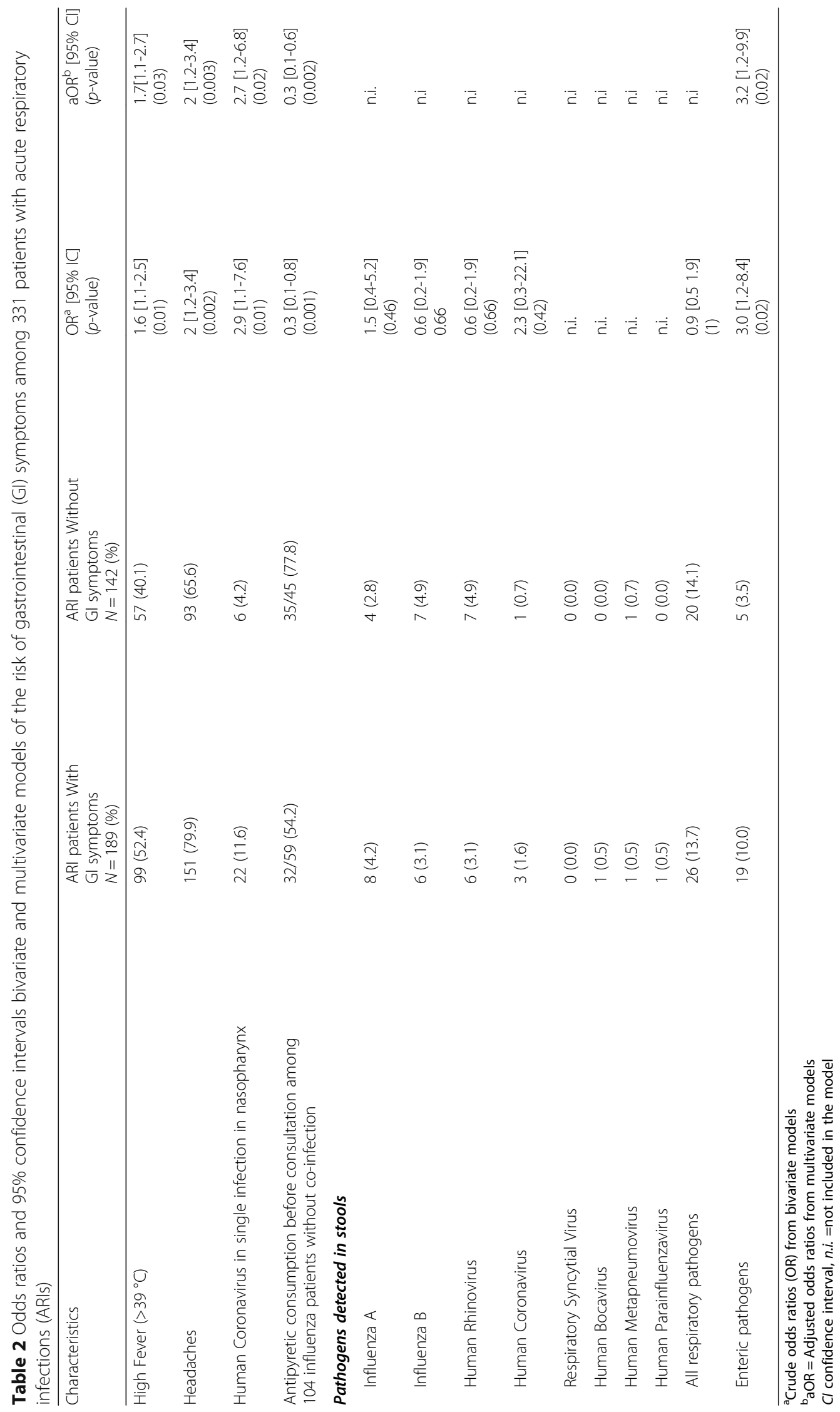




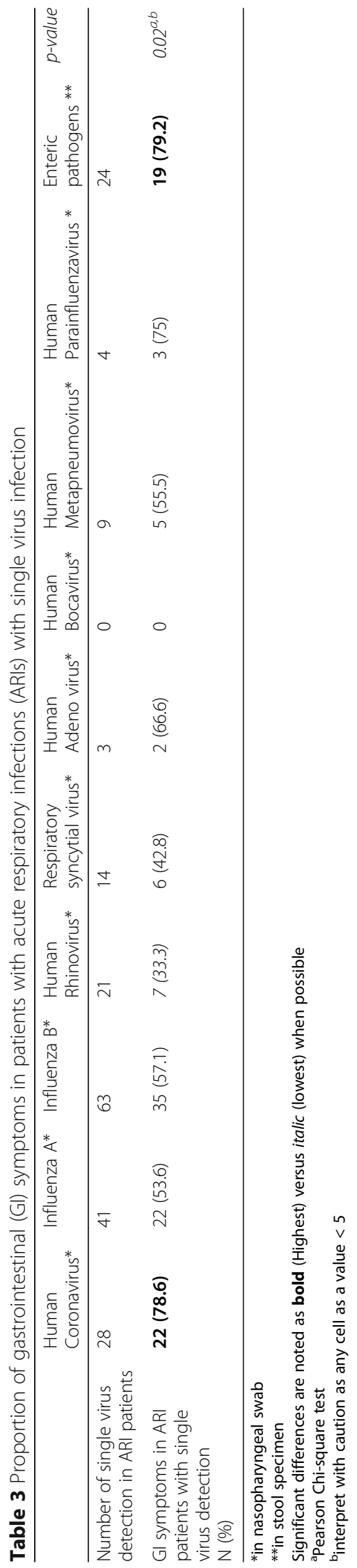


GI symptoms in ARI patients. However, among the 104 patients with influenza infection, 56.7\% (59/104) presented GI symptoms. The mouse model used by Wang [20] showed that influenza infection through a mechanism dependent on type I interferons (IFN-Is) can alter the composition of the intestinal microbiota, resulting in immunological dysregulation that may promote inflammatory gut disorders. The number of Escherichia coli (E.coli) in the intestinal tract increased, perhaps leading to intestinal immune injury. A similar study [30] reported that influenza-induced IFN-Is enhance susceptibility to Salmonella intestinal colonization and dissemination during secondary Salmonella-induced colitis through suppression of host intestinal immunity. The systemic role for IFN-Is in altering the intestinal microbial balance after influenza infection need to be explored.

Interestingly, we found that the consumption of antipyretic drugs before consultation seemed to reduce the risk of developing GI symptoms among laboratory-confirmed influenza patients. This result is in line with previous studies that showed that paracetamol dramatically decreases the morbidity associated with influenza, thereby reducing the clinical symptoms associated with influenza virus infection [31,32]. Therefore, the consumption of antipyretic drugs before consultation may lead to the underestimation of the frequency of GI symptoms in patients with laboratory-confirmed influenza.

The strengths of this study include its prospective multicentrer design and study length spanning two consecutive ARI seasons, standardized patient screening by the participant GPs, centralized confirmation of microbiological data, the simultaneous search of respiratory pathogens in nasopharyngeal and stool samples and the presence of enteric pathogens (viruses and bacteria) in stool, and other confounding factors that might also cause GI symptoms.

This study did have several limitations. First, the main limitation of this study was the lack of culturing of respiratory viruses from stool samples to determine if RT-qPCR detection represented the presence of viable virus. The detection of respiratory viruses in the stool could simply be RNA/DNA from viruses that were swallowed. A recent study showed that a swallowed virus could be detected in stools if protective mechanisms render it resistant to gastric acid and bile/pancreatic juice [33]. High viscosity of mucus could protect influenza viruses from inactivation in the gastrointestinal environment, accounting for detection of the virus in feces [33]. Second, the number of patients included here did not allow the identification of meaningful associations by sub-analyses. Studies with a small-tomoderate sample size that employ logistic regression have been reported to overestimate the effect measure [34]. Third, we did not collect data pertaining to GI symptoms after GP consultation, which hampered the interpretation of the results.

\section{Conclusion}

In conclusion, except for ARI patients with enteric pathogens in stool samples, the presence of GI symptoms in ARI patients could not be explained by the detection of respiratory pathogens in stools. However, the detection of enteric pathogens in stool samples could explained by the presence of GI symptoms in some of ARI cases. The biological mechanisms explaining the association between the presence of HCoVs in nasopharynx and GI symptoms need to be explored.

\section{Additional files}

Additional file 1: Gastrointestinal symptoms' proportion by respiratory pathogens infection found in previous studies. (PDF $210 \mathrm{~kb}$ )

Additional file 2: Detection number and/or detection rate of respiratory viruses in stool of Acute Respiratory Infection (ARI) patients found in previous studies. (PDF $93 \mathrm{~kb}$ )

Additional file 3: a) Seasonal distribution of influenza viruses identified in patients consulting for an Acute Respiratory Infection (ARI) during 2014-2015 season and 2015-2016 season. (PDF 389 kb)

Additional file 4: List of information collected by General Practitioners in the Case Report Form during consultation recruiting of patients with ARI. (DOCX $20 \mathrm{~kb}$ )

\section{Abbreviations}

ARI: Acute Respiratory Infection; CRF: Case report form; EV: Enterovirus; FDT: Fast track diagnostic; GI: Gastrointestinal; GP: General practitioner; HAdV: Human adenovirus; HBoV: Human Bocavirus; HCoV: Human Coronavirus; HMTP: Human Metapneumovirus; HPeV: Human Parechovirus; HPIV: Human Parainfluenza virus; HRV: Human Rhinovirus; M.pneu: Mycoplasma pneumoniae; RSV: Respiratory Syncytial virus; RT-qPCR: Real-time Reverse Transcription-polymerase Chain Reaction test

\section{Acknowledgements}

We thank Dr. Agostini, Dr. Alexandre-Favrichon, Dr. Armengaud, Dr. Bardoux, Dr. Biancale, Dr. Cadart, Dr. Casanova, Dr. Cegarra, Dr. Chabrier, Dr. Chemin, Dr. Corteggiani, Dr. Dahan, Dr. Damalix, Dr. Demure, Dr. Denis, Dr. Diebolt, Dr. Docquier, Dr. Duhamel, Dr. Erminj-Arfi, Dr. Fauquier, Dr. Flamerion, Dr. Grossi, Dr. Guidicelli, Dr. Guiot, Dr. Lafosse, Dr. Le Glaunec, Dr. Le Vigouroux, Dr. Leparc, Dr. Marcon-Mattei, Dr. Martorana, Dr. Mas, Dr. Maviel, Dr. Medori, Dr. Meyrand, Dr. Miniconi, Dr. Mondet, Dr. Moretti, Dr. Nogrel, Dr. Philibert, Dr. Pinelli, Dr. Rambaud, Dr. Samzun, Dr. Torrente, Dr. Vittoz for their involvement in this study.

\section{Funding}

NA.

\section{Availability of data and materials}

The dataset during and/or analysed during the current study are available from the corresponding author on reasonable request.

\section{Authors' contributions}

LM, principal investigator of this study. Implementation of study protocol, laboratory analyses, statistical analyses, first draft manuscript, contributing in all sections. MS, participated to laboratory analyses, and in manuscript revision. $C L$, revising manuscript and contributing to discussion section. BT, revising manuscript and contributing to discussion section. CPE, revising manuscript and contributing to discussion section. VDWS, revising manuscript and contributing to discussion section. $\mathrm{HT}$, revising manuscript and contributing to discussion section. $C R$, revising manuscript and contributing to result and discussion sections. AF, principal investigator of this study, implementation of study protocol, analyses and interpretation, first draft manuscript and revising all sections in the manuscript. All authors read and approved the final manuscript. 


\section{Ethics approval and consent to participate}

This study was approved by the Ethics Committee (CPP SUD MEDITERRANEE $V$, ref. number 14.078). The protocol was conducted in accordance with the Helsinki declaration. All samples were coded and tested anonymously. None of the authors collected samples. Samples were collected and sent to the test laboratory by GPs involved in the research project. Patient information was stored according to national regulations and access to such data was restricted (permission Commission nationale de l'informatique et des libertés $471,393)$. The patient's identities were not disclosed at any stage. Written informed consent was obtained from patients by the GP's. For children under the age of 18, parents or legal guardians gave permission for their participation in this project. Consent from the child was also obtained, depending on her/his age and maturity.

\section{Consent for publication}

Not applicable.

\section{Competing interests}

The authors declare that they have no competing interests.

\section{Publisher's Note}

Springer Nature remains neutral with regard to jurisdictional claims in published maps and institutional affiliations.

\section{Author details}

'EA7310, Laboratoire de Virologie, Université de Corse-Inserm, 20250 Corte, France. ${ }^{2}$ Institut Pierre Louis d'Epidémiologie et de Santé Publique, Sorbonne Universités, UPMC Univ Paris 06, UMR_S 1136, 56, Boulevard Vincent Auriol, 81393-75646 Paris, France. ${ }^{3}$ INSERM, UMR_S 1136, Institut Pierre Louis d'Epidémiologie et de Santé Publique, 56, Boulevard Vincent Auriol, 81393-75646 Paris, France. ${ }^{4}$ Pasteur Institute, Virology Department, Epidemiology and Physiopathology of Oncogenic Viruses Unit, F-75015 Paris, France. ${ }^{5}$ UMR CNRS 3569, 75015 Paris, France. ${ }^{6}$ Sorbonne Paris Cité, Cellule Pasteur, Université Paris Diderot, Institut Pasteur, 75015 Paris, France. ${ }^{7}$ Pasteur Institute, Virology Department, Molecular Genetics of RNA Viruses Unit, F-75015 Paris, France. ${ }^{8}$ Université Paris Diderot, Sorbonne Paris Cité, Unité de Génétique Moléculaire des Virus à ARN, EA302, F-75015 Paris, France. ${ }^{9}$ Sorbonne Université, UPMC Université Paris 06, Institut Pierre-Louis d'Épidémiologie et de Santé Publique (IPLESP UMRS 1136), Paris, France. ${ }^{10}$ Hôpital Ambroise Paré, service de médecine interne, Boulogne-Billancourt, France. ${ }^{11}$ UFR des Sciences de la Santé Simone-Veil, Université Versailles Saint Quentin en Yvelines, Versailles, France. ${ }^{12}$ UMR "Emergence des Pathologies Virales" (EPV: Aix-Marseille Univ - IRD 190 - Inserm 1207 - EHESP) \& Fondation IHU Méditerranée Infection, APHM Public Hospitals of Marseille, Marseille, France.

Received: 3 February 2017 Accepted: 6 November 2017 Published online: 22 November 2017

\section{References}

1. Moreno-Valencia Y, Hernandez-Hernandez VA, Romero-Espinoza JA, Coronel-Tellez RH, Castillejos-Lopez M, Hernandez A, Perez-Padilla R, Alejandre-Garcia A, de la Rosa-Zamboni D, Ormsby CE, et al. Detection and characterization of respiratory viruses causing acute respiratory illness and asthma exacerbation in children during three different season (2011-2014) in Mexico City. Influenza Other Respir Viruses. 2015;9(6):287-92.

2. Feng L, Li Z, Zhao S, Nair H, Lai S, Xu W, Li M, Wu J, Ren L, Liu W, et al. Viral etiologies of hospitalized acute lower respiratory infection patients in China, 2009-2013. PLoS One. 2014;9(6):e99419.

3. Ursic T, Jevsnik M, Zigon N, Krivec U, Beden AB, Praprotnik M, Petrovec M. Human bocavirus and other respiratory viral infections in a 2-year cohort of hospitalized children. J Med Virol. 2012;84(1):99-108.

4. Dominguez SR, Robinson CC, Holmes KV. Detection of four human coronaviruses in respiratory infections in children: a one-year study in Colorado. J Med Virol. 2009;81(9):1597-604.

5. Wootton SH, Aguilera EA, Wanger A, Jewell A, Patel K, Murphy JR, Piedra PA Detection of NH1N1 influenza virus in nonrespiratory sites among children. Pediatr Infect Dis J. 2014;33(1):95-6.

6. Meury S, Zeller S, Heininger U. Comparison of clinical characteristics of influenza and respiratory syncytial virus infection in hospitalised children and adolescents. Eur J Pediatr. 2004;163(7):359-63.
7. Bach N, Cuvillon D, Brouard J, Lafay F, Freymuth F, Legrand L, Guillois B, Duhamel JF. Acute respiratory tract infections due to a human metapneumovirus in children: descriptive study and comparison with respiratory syncytial virus infections. Arch Pediatr. 2004;11(3):212-5.

8. Wald TG, Shult P, Krause P, Miller BA, Drinka P, Gravenstein S. A rhinovirus outbreak among residents of a long-term care facility. Ann Intern Med. 1995;123(8):588-93.

9. Landi KK, Coleman AT. Sudden death in toddlers caused by influenza B infection: a report of two cases and a review of the literature. J Forensic Sci. 2008;53(1):213-5.

10. Savolainen-Kopra C, Simonen-Tikka ML, Klemola P, Blomqvist S, Suomenrinne S, Nanto-Salonen K, Simell O, Roivainen M. Human rhinoviruses in INDIS-study material-evidence for recovery of viable rhinovirus from fecal specimens. J Med Virol. 2013;85(8):1466-72.

11. Paloniemi M, Lappalainen S, Salminen M, Katka M, Kantola K, Hedman L, Hedman K, Soderlund-Venermo M, Vesikari T. Human bocaviruses are commonly found in stools of hospitalized children without causal association to acute gastroenteritis. Eur J Pediatr. 2014;173(8):1051-7.

12. Paloniemi M, Lappalainen S, Vesikari T. Commonly circulating human coronaviruses do not have a significant role in the etiology of gastrointestinal infections in hospitalized children. J Clin Virol. 2015;62:114-7.

13. Chan MC, Lee N, Chan PK, To KF, Wong RY, Ho WS, Ngai KL, Sung JJ. Seasonal influenza a virus in feces of hospitalized adults. Emerg Infect Dis. 2011;17(11):2038-42

14. von Linstow ML, Eugen-Olsen J, Koch A, Winther TN, Westh H, Hogh B: Excretion patterns of human metapneumovirus and respiratory syncytial virus among young children. Eur J Med Res 2006, 11(8):329-335.

15. Kocer ZA, Obenauer J, Zaraket H, Zhang J, Rehg JE, Russell CJ, Webster RG. Fecal influenza in mammals: selection of novel variants. J Virol. 2013;87(21): $11476-86$.

16. Arena C, Amoros JP, Vaillant V, Ambert-Balay K, Chikhi-Brachet R, Jourdan-Da Silva N, Varesi L, Arrighi J, Souty C, Blanchon T, et al. Acute diarrhea in adults consulting a general practitioner in France during winter: incidence, clinical characteristics, management and risk factors. BMC Infect Dis. 2014;14:574.

17. Letrilliart L, Desenclos JC, Flahault A. Risk factors for winter outbreak of acute diarrhoea in France: case-control study. BMJ. 1997;315(7123):1645-9.

18. Wallensten A, Oliver I, Lewis D, Harrison S. Compliance and side effects of prophylactic oseltamivir treatment in a school in South West England. Euro Surveill. 2009;30;14(30):19285.

19. Minodier L, Charrel RN, Ceccaldi PE, van der Werf S, Blanchon T, Hanslik T, Falchi A. Prevalence of gastrointestinal symptoms in patients with influenza, clinical significance, and pathophysiology of human influenza viruses in faecal samples: what do we know? Virol J. 2015;12:215.

20. Wang J, Li F, Wei H, Lian ZX, Sun R, Tian Z. Respiratory influenza virus infection induces intestinal immune injury via microbiota-mediated Th17 cell-dependent inflammation. J Exp Med. 2014;211(12):2397-410.

21. Valleron AJ, Bouvet E, Garnerin P, Menares J, Heard I, Letrait S, Lefaucheux J. A computer network for the surveillance of communicable diseases: the French experiment. Am J Public Health. 1986;76(11):1289-92.

22. Legrand J. French GPS sentinelles network: study of the reprensentativity and participation of GPs sentinel physicians. Paris (France): University Pierre et Marie Curie In; 2001.

23. ECDC case definition. http://eur-lex.europa.eu/legal-content/EN/TXT/PDF/ ?uri=CELEX:32012D0506\&qid=1428573336660\&from=EN\#page $=16$.

24. Ninove L, Nougairede A, Gazin C, Thirion L, Delogu I, Zandotti C, Charrel RN, De Lamballerie X. RNA and DNA bacteriophages as molecular diagnosis controls in clinical virology: a comprehensive study of more than 45,000 routine PCR tests. PLoS One. 2011;6(2):e16142.

25. Biere B, Bauer B, Schweiger B. Differentiation of influenza B virus lineages Yamagata and Victoria by real-time PCR. J Clin Microbiol. 2010;48(4):1425-7.

26. Information for molecular diagnosis of influenza virus - update. http://www. who.int/influenza/gisrs_laboratory/molecular_diagnosis/en/.

27. Yip CC, Lam CS, Luk HK, Wong EY, Lee RA, So LY, Chan KH, Cheng VC, Yuen KY, Woo PC, et al. A six-year descriptive epidemiological study of human coronavirus infections in hospitalized patients in Hong Kong. Virol Sin. 2016;31(1):41-8.

28. Jevsnik M, Steyer A, Pokorn M, Mrvic T, Grosek S, Strle F, Lusa L, Petrovec M. The role of human coronaviruses in children hospitalized for acute Bronchiolitis, acute gastroenteritis, and febrile seizures: a 2-year prospective study. PLoS One. 2016;11(5):e0155555.

29. Esposito S, Bosis S, Niesters HG, Tremolati E, Begliatti E, Rognoni A, Tagliabue C, Principi N, Osterhaus AD. Impact of human coronavirus 
infections in otherwise healthy children who attended an emergency department. J Med Virol. 2006;78(12):1609-15.

30. Deriu E, Boxx GM, He X, Pan C, Benavidez SD, Cen L, Rozengurt N, Shi W, Cheng G. Influenza virus affects intestinal microbiota and secondary salmonella infection in the gut through type I Interferons. PLoS Pathog. 2016;12(5):e1005572.

31. Lauder SN, Taylor PR, Clark SR, Evans RL, Hindley JP, Smart K, Leach H, Kidd EJ, Broadley KJ, Jones SA, et al. Paracetamol reduces influenza-induced immunopathology in a mouse model of infection without compromising virus clearance or the generation of protective immunity. Thorax. 2011;66(5):368-74.

32. Danno K, Cognet-Dementhon B, Thevenard G, Duru G, Allaert FA, Bordet MF. Management of the early symptoms of influenza-like illnesses and ear, nose and throat (ENT) disorders by pharmacists. Homeopathy. 2014;103(4):239-49.

33. Hirose R, Nakaya T, Naito Y, Daidoji T, Watanabe Y, Yasuda H, Konishi H, Itoh $Y$. Mechanism of human influenza virus RNA persistence and virion survival in feces: mucus protects virions from acid and digestive juices. J Infect Dis. 2017;1;216(1):105-9.

34. Nemes S, Jonasson JM, Genell A, Steineck G. Bias in odds ratios by logistic regression modelling and sample size. BMC Med Res Methodol. 2009;9:56.

\section{Submit your next manuscript to BioMed Central} and we will help you at every step:

- We accept pre-submission inquiries

- Our selector tool helps you to find the most relevant journal

- We provide round the clock customer support

- Convenient online submission

- Thorough peer review

- Inclusion in PubMed and all major indexing services

- Maximum visibility for your research

Submit your manuscript at www.biomedcentral.com/submit 